\title{
Numerical Analysis of Heat Transfer in Unsteady Nanofluids in a Small Pipe with Pulse Pressure
}

\author{
Cheol Park ${ }^{1}$, Junhyo Kim², Jungpil Noh ${ }^{3}$, Sunchul Huh ${ }^{4}$, Byeongkeun $\mathrm{Choi}^{5}$, \\ hanshik Chung ${ }^{6}, *$ HyoMin Jeong ${ }^{7}$ \\ ${ }^{1}$ Department of Energy and Mechanical Engineering, Gyeongsang National University. Institute of Marine Industry, \\ Cheondaegukchi-Gil 38, Tongyeong, Gyeongnam, 650-160, South Korea \\ ${ }^{2}$ Department of Marine Engineering, Mokpo National MaritimeUniversity,61 dorim-ri, \\ 1666 Yeongsan-ro. cheonggye-myeon, Muan-gun, jeonnam, South Korea \\ ${ }^{3,4,5,6,7}$ Department of Energy and Mechanical Engineering, Gyeongsang National University · Institute of Marine Industry, \\ Cheondaegukchi-Gil 38, Tongyeong, Gyeongnam, 650-160, South Korea
}

\begin{abstract}
In the present paper, developing turbulence forced convection flows were numerically investigated by using water- $\mathrm{Al}_{2} \mathrm{O}_{3}$ nano-fluid through a circular compact pipe which has $4.5 \mathrm{~mm}$ diameter. Each model has a steady state and uniform heat flux $(U H F)$ at the wall. The whole numerical experiments were processed under the RPM 100 to 500 and the nano-fluid models were made by the Alumina volume fraction. Single-phase fluid models were defined through nano-fluid physical and thermal properties calculations, Two-phase models (mixture granular model) were processed in 100nm diameter. The results show that comparison of nusselt number and heat transfer rate are improved as the $\mathrm{Al}_{2} \mathrm{O}_{3}$ volume fraction increased. All of the numerical flow simulations are processed by the FLUENT. The results show an increase from volume fraction concentration and an increase in heat transfer coefficient with increasing RPM.
\end{abstract}

Keywords - nanofluid, mixture, alumina, nusselt number, heat transfer coefficient, Pulsation pressure.

\section{INTRODUCTION}

Heat transfer fluids play an important role in many industries, including power plants; production processes, transportation and electronics, and the heat transfer characteristics of thermal fluids play an important role in the development of energy efficient heat transfer devices. Past improvements have been based on structural changes and the addition of heat transfer areas, vibrations on the surface of the heat, injection or inhalation of fluids and the application of electrons or magnetic fields. These enhancement techniques rarely meet the increase in heat transfer coefficient and, in this connection; there is a strong demand for the development of advanced heat transfer fluids with higher heat transfer properties. Therefore, a number of recent studies on nanofluids for experimental convective heat transfer through circular tubes have been conducted by senior scholars. However, nanofluid research is still in the hot debate and investigation. In addition, research on the pulse pressure has been actively carried out all over the world, and many research results have been published especially in the field of noise vibration. Non-steady pulsating flow phenomena will be generated by internal smoke and reciprocating compressors. The pulsating pressure in the internal combustion engine will be the silencer part. The function of this silencer is to reduce the pulsation pressure inside the silencer as well as to reduce the back pressure.

Maxwell [1,2] has demonstrated that increasing the volume fraction of solid particles can increase the thermal conductivity of the mixture. The particle diameter currently available for particle manufacturing technology development is smaller than 100 $\mathrm{nm}$, called nano-size. This effort allows the particle mixing fluid to increase the thermal conductivity of the heat transfer fluid by increasing the critical thermal conductivity. In addition, solid nanoparticle colloids are very stable and do not exhibit significant sedimentation under static conditions after weeks or months. In addition, solid colloids float easily when you reduce particle size. Therefore, nanofluidic technology is expected to be suitable for heat transfer fluids.

Mohamad and viskanta [3] studied the abnormal natural convection for a low prandtl number of fluids in the cavity, and patterson and Imberger [4] conducted a study on the abnormal natural circulation in a square cavity. Hellims and Churchill [5] numerically studied the natural convection in an unsteady state in a closed vessel. Therefore, this study focuses on the nanofluid only for pulsating pressure in a small tube with a pulse pressure. The purpose of this study is to verify the 
numerical analysis technique in terms of the fluidity of the nanofluids in a small tube with a pulsating pressure through numerical analysis. The purpose is to secure the data.

\section{Mathematical Modeling}

\subsection{Geometry and boundary condition}

Fig. 1a shows the actual model of geometry and Fig. 1b is the part of the Two-dimensional Mesh. One of the main purpose of this simulation is trying to understand the near wall behavior of nano-particles, velocity distribution perpendicular to the pipe surface and drag coefficient at the near of pipe wall, so the relatively concentrated mesh in the near wall area is needed. As a result, the mesh has a non-uniform quadratic mesh. The bottom horizontal line is an axis which makes Three-dimensional pipe model at the asymmetric environment. The upper horizontal line is a wall with Uniform heat flux. The tube consisted with a diameter (D) of $4.5 \mathrm{~mm}$ and a length (L) of $1.17 \mathrm{~m}$. Nanofluids is composed of $\mathrm{Al}_{2} \mathrm{O}_{3}$ particles and water have the physical properties such as Table.1[6]. The total flow rate for each fluid model is input at a constant temperature of $293 \mathrm{~K}$ and the axial velocity is defined as pressure change over time at 100,300,500RPM and the wall surface has a Heat flux of 5000 (w/ m2).

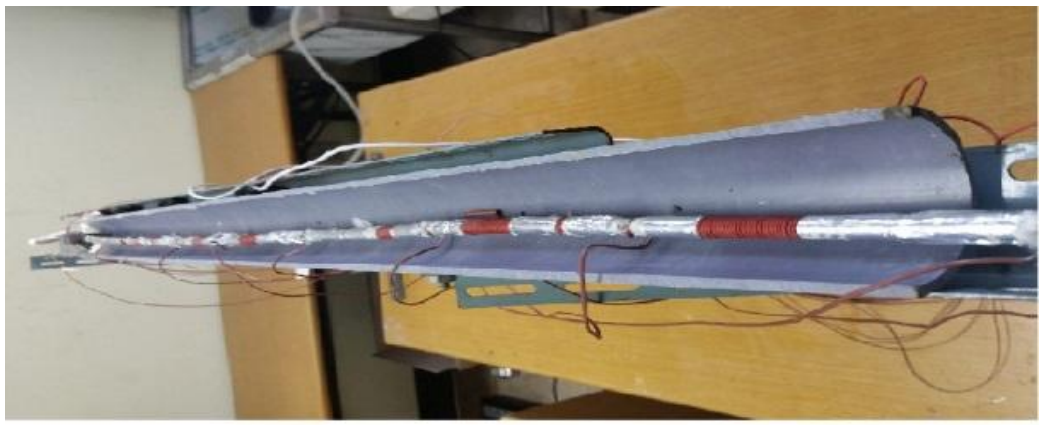

(a)

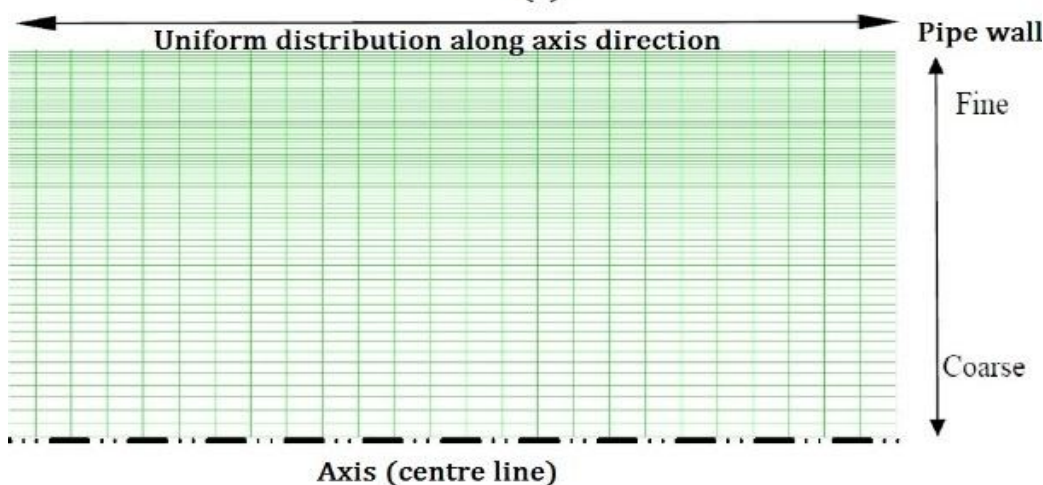

(b)

Figure 1. PART OF THE MeSh OF COMPUTATIONAL CELl. 80 X 8000 With 0.96 Ratio

TABLE 1

$\mathrm{Al}_{2} \mathrm{O}_{3}$ NANOPARTICLE AT TEMPERATURE OF 293K

\begin{tabular}{|c|c|c|c|c|}
\hline Chemical formula & Density $\left(\mathbf{k g} / \mathbf{m}^{\mathbf{3}}\right)$ & $\begin{array}{c}\text { Heat } \\
\text { conductivity }(\boldsymbol{W} / \mathbf{m} \boldsymbol{K})\end{array}$ & $\begin{array}{c}\text { Specific } \\
\text { heat }(\boldsymbol{J} / \mathbf{k g} \boldsymbol{K})\end{array}$ & $\begin{array}{c}\text { Spherical } \\
\text { diameter }(\boldsymbol{n m})\end{array}$ \\
\hline $\mathrm{Al}_{2} \mathrm{O}_{3}$ & 3880 & 36 & 773 & 100 \\
\hline
\end{tabular}

\subsection{Governing equation}

The single-phase model is investigated for the comparison of mixture model as prescribed. Following equations are representing the mathematical formulation of the single-phase model and of the continuous phase of the mixture model. The exact $\mathrm{k}-\varepsilon$ equations contain many unknown and un-measurable term [6-8]

Energy equation: 


$$
\operatorname{div}(\rho \overrightarrow{\mathrm{V}} \mathrm{CpT})=\operatorname{div}(\operatorname{kgrad} T)+S_{e}
$$

turbulent kinetic energy $\mathrm{k}$

$$
\frac{\partial(\rho k)}{\partial t}+\frac{\partial\left(\rho k u_{i}\right)}{\partial x_{i}}=\frac{\partial}{\partial x_{j}}\left[\frac{\mu_{t}}{\sigma_{k}} \frac{\partial k}{\partial x_{j}}\right]+2 \mu_{t} E_{i j} E_{i j}-\rho \epsilon
$$

dissipation $\varepsilon$

$$
\frac{\partial(\rho \epsilon)}{\partial t}+\frac{\partial\left(\rho \epsilon u_{i}\right)}{\partial x_{i}}=\frac{\partial}{\partial x_{j}}\left[\frac{\mu_{t}}{\sigma_{\epsilon}} \frac{\partial \epsilon}{\partial x_{j}}\right]+C_{1 \epsilon} 2 \mu_{t} E_{i j} E_{i j}-C_{2 \varepsilon} \rho \frac{\epsilon^{2}}{k}
$$

And k- $\varepsilon$ equation of represents velocity component in corresponding direction $\left(u_{i}\right)$, represents component of rate of deformation $\left(E_{i j}\right)$, represents eddy viscosity $\left(\mu_{t}\right)$ (Rate of change of $\mathrm{k}$ or $\varepsilon+$ Transport of $\mathrm{k}$ or $\varepsilon$ by convection $=$ Transport of $\mathrm{k}$ or $\varepsilon$ by diffusion + Rate of production of $\mathrm{k}$ or $\varepsilon$ - Rate of destruction of $\mathrm{k}$ or $\varepsilon$ )

Conservation of mass:

$$
\frac{\delta \rho_{m}}{\delta t}+\nabla \cdot\left(\rho_{m} u_{m}\right)=0
$$

Where $u_{m}$ is the mass-averaged velocity?

$$
u_{m}=\frac{\sum_{k=1}^{n} \alpha_{k} \rho_{k} u_{k}}{\rho_{m}}
$$

and $\rho_{m}$ is the mixture density with $\alpha_{k}$ volume fraction of phase $k$ :

$$
\rho_{m}=\sum_{k=1}^{n} \alpha_{k} \rho_{k}
$$

Momentum equation for single-phase:

$$
\operatorname{div}(\rho \overrightarrow{\mathrm{V}} \overrightarrow{\mathrm{V}})=-\operatorname{grad} P+\nabla \cdot(\mu \nabla \overrightarrow{\mathrm{V}})+S_{m}
$$

Momentum equation for multi-phase:

$$
\nabla \cdot \sum_{k=1}^{n} \alpha_{k} \rho_{k} u_{k} u_{k}=\nabla \cdot\left(\rho_{m} u_{m} u_{m}\right)+\nabla \cdot \sum_{k=1}^{n} \alpha_{k} \rho_{k} u_{M k} u_{M k}
$$

The compression and viscous lose by heat are assumed to be excluded in the energy equation. The source/sink terms $S_{m}$ and $S_{e}$ represent the unitize effects of energy and momentum exchange with base fluid. These are zero value in the single-phase model. Momentum equation of multi-phase are affected by volume fraction $(\alpha)$, velocity of phase $\left(u_{k}\right)$, diffusion velocity $\left(u_{M k}\right)$.

The determinations of particle motion are particle mass $\left(\mathrm{m}_{p}\right)$, cross-sectional area of the particle $\left(\mathrm{A}_{p}\right)$, drag coefficient $\left(\mathrm{C}_{D}\right)$, slip velocity $\left(u_{c p}\right)$.

The drag force in this study is following Clift et al equation (7) for single rigid spherical particle in a fluid:

$$
\mathrm{F}_{D}=-\frac{1}{2} A_{p} \rho_{c} C_{D}\left|u_{C p}\right| u_{C p}-\frac{1}{2} V_{p} \rho_{c} \frac{d u_{C p}}{d t}-6 \gamma_{p}^{2} \sqrt{\pi \rho_{c} \mu_{c}} \int_{0}^{t} \frac{d u_{C p}}{\frac{d s}{\sqrt{t-s}}} d s
$$

\subsection{Numerical approach}

The computational fluid dynamic code FLUENT 16.1 is employed to solve the present problem. The governing Eqs. (1)-(3) are solved by control volume approach. The algebraic "discretize equations," resulting from spatial inter-fraction process, are sequentially solved throughout the physical domain considered. ANSYS Fluent 16.1 solves the systems resulting from discretization schemes using a numerical method. For the convective and diffusive terms, a second order upwind method was used. Pressure and velocity were coupled using Semi Implicit Method for Pressure Linked Equations (SIMPLE) in singlephase. To calculate the pulse pressure, Figure 2. The PISO algorithm was used to calculate the anomalous state as a complete negative solution. The continuity equation and the momentum equation are used to calculate the pressure inside the small tube. 
The turbulence model is based on the standard model $\mathrm{k}-\varepsilon$ model which has already proved its engineering validity. The convergence judgment of the residuals was regarded as convergence when the residual value reached 10 or less.

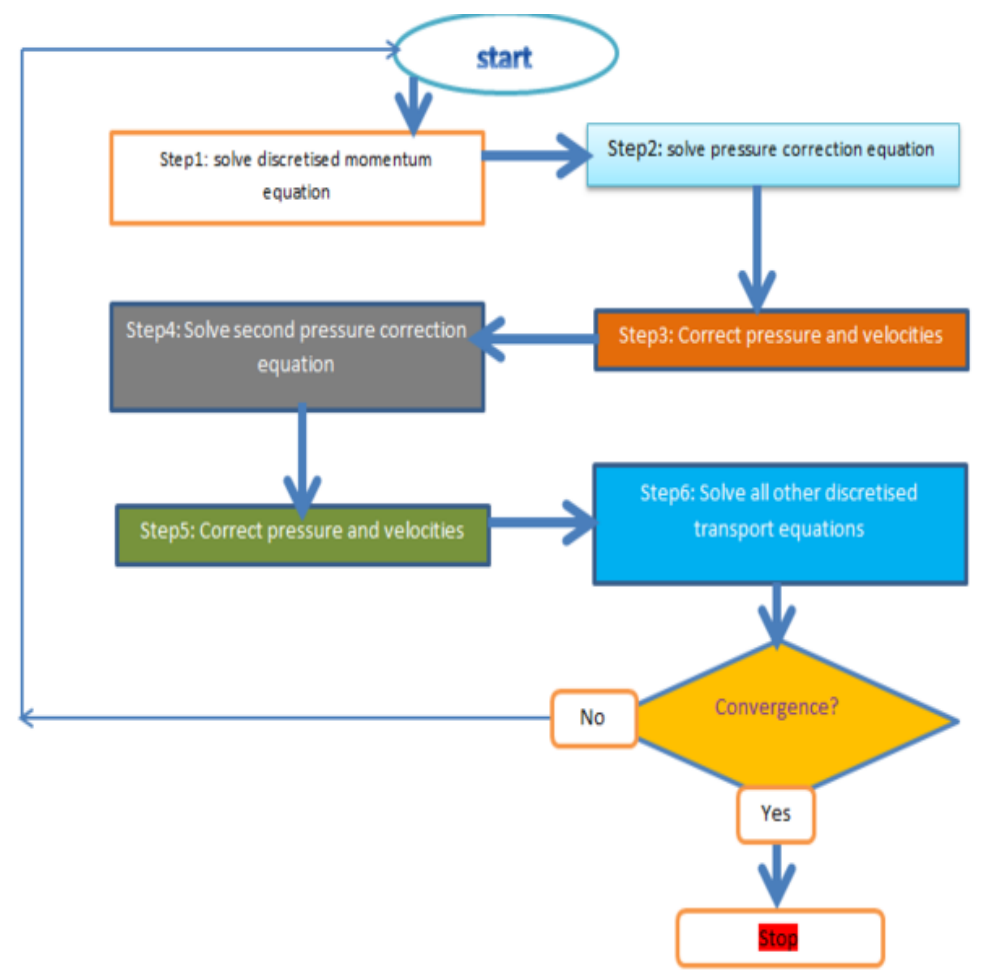

Figure 2. FLOW ChART OF PISO ALGORITHM

As already seen for the SIMPLE algorithm, the steps 4 and 5 can be repeated for a prescribed number of times to correct for non-orthogonality.

\section{RESULTS}

The In this work a number of numerical simulations have been performed to study forced convective heat transfer of $\mathrm{Al}_{2} \mathrm{O}_{3}$ water in a circular tube under turbulence flow and results were conducted to employing the single phase and mixture model for $\varphi=1 \%$ to $4 \%, 100$ to500RPM as $\mathrm{q}=5000 \mathrm{~W} / \mathrm{m}^{\wedge} 2$ with a constant state. In all cases the size of the spherical particles is $100 \mathrm{~nm}$.

Thermal entrance length depends on Prandtl number.[9] So when concentration increases Pr number also increases and consequently, thermal entrance length becomes greater.

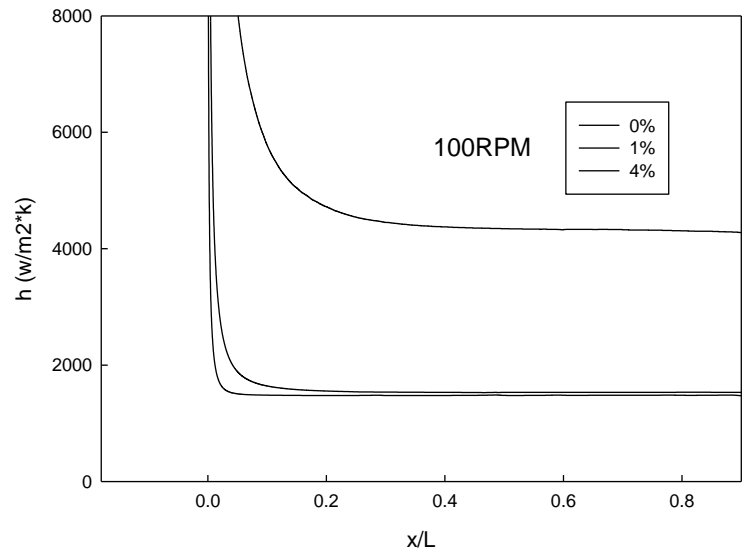

(a)

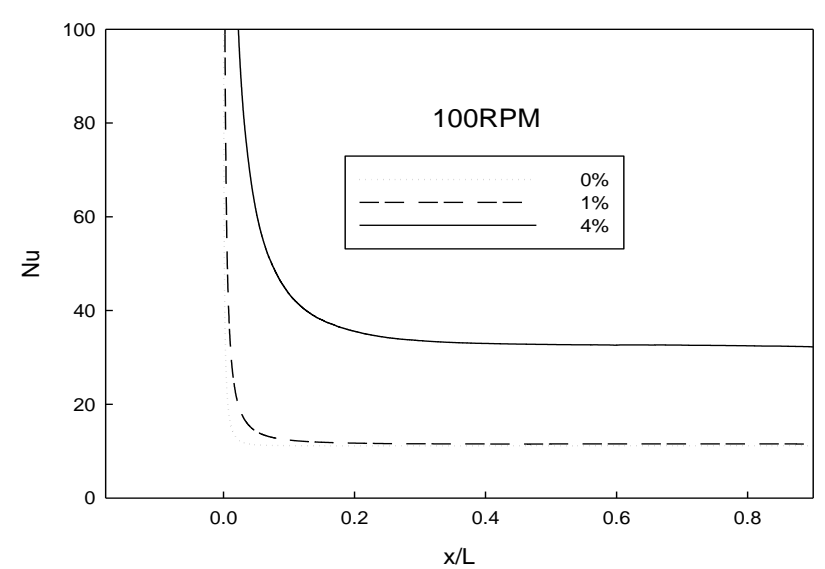

(b)

FIGURE 3.(A) 100RPM, HEAT TRANSFER COEFFICIENT FOR $\mathrm{Al}_{2} \mathrm{O}_{3}$-WATER, (B)100RPM, NUSSELT NUMBER

As shown in Fig. 3 (a), the difference between $0 \%$ and $1 \%$ seems to be insignificant in the range of $0.1 \mathrm{x} / \mathrm{Lmm}$, but the heat transfer rate of $4 \% \mathrm{Al}_{2} \mathrm{O}_{3}$ is 2 times larger than $0,1 \%$ Respectively. Likewise, in figure (b) 
The transmission rate of 0 and $1 \% \mathrm{Al}_{2} \mathrm{O}_{3}$ is less than 10 , but $4 \%$ nanofluids can be seen to have more than twice the Nusselt number.

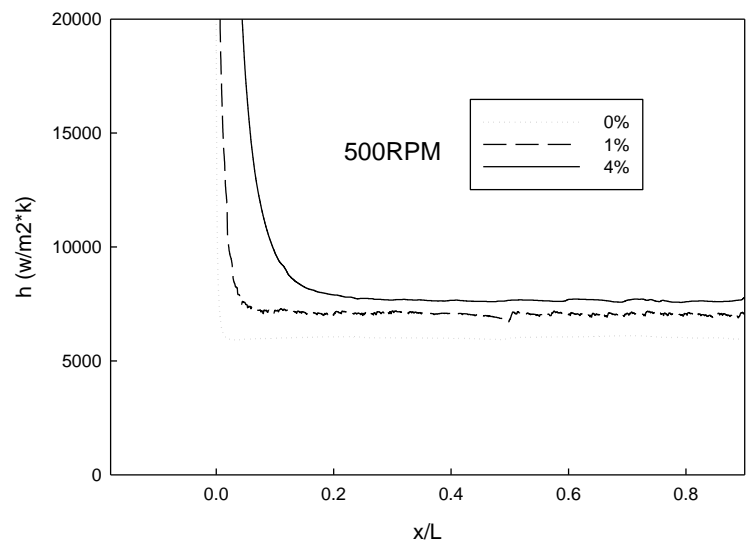

(a)

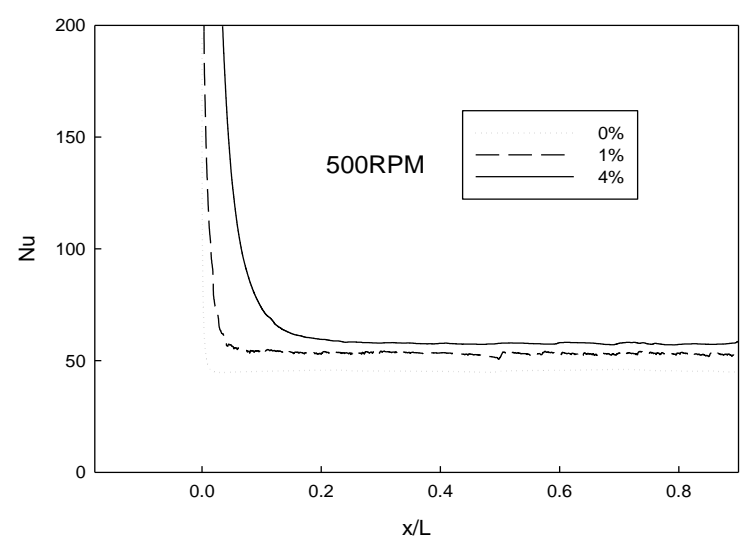

(b)

FIGURE 4.(a) 500RPM, HEAT TRANSFER COEFFICIENT FOR $\mathrm{Al}_{2} \mathrm{O}_{3}$-WATER, (b) 500RPM, NUSSELT NUMBER

In Fig. 4 (a), unlike 100RPM, the phenomena appearing more than twice as much as $0 \%, 1 \%$ and $4 \%$ are not shown in the figure. This phenomenon can be grasped by increasing the internal pressure at 500 RPM. Also, in Fig. (B), the Nusselt number seems to be closer to $1 \% \mathrm{Al}_{2} \mathrm{O}_{3}$ than $4 \%$.

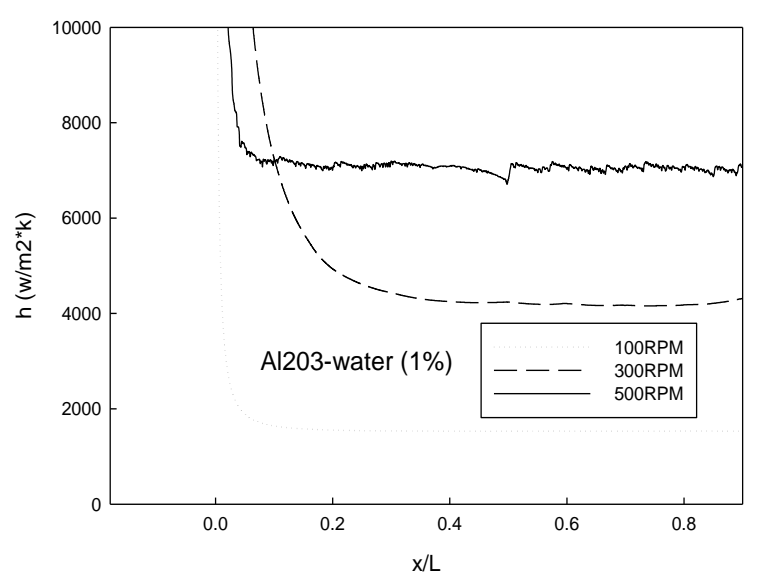

(a)

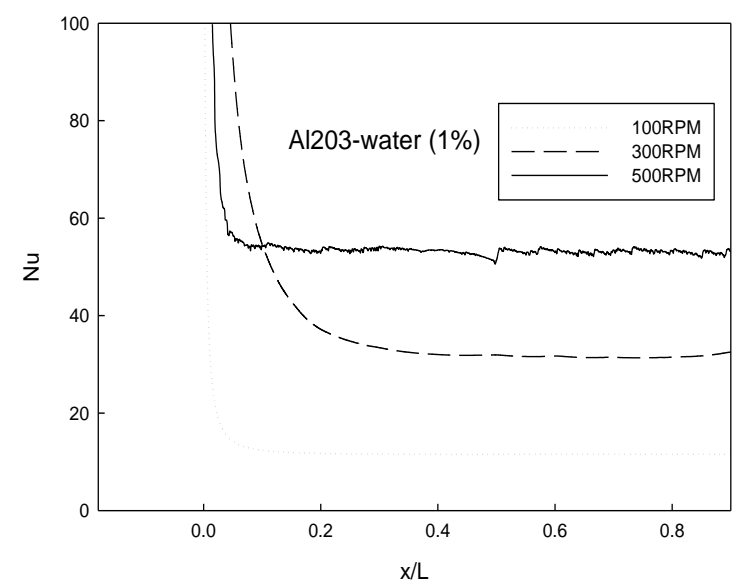

(b)

\section{FIgURE 5.(a) $\mathrm{Al}_{2} \mathrm{O}_{3}$-WATER, HEAT TRANSFER COEFFICIENT FOR 100 TO 500RPM, (B) $\mathrm{Al}_{2} \mathrm{O}_{3}$-WATER, NUSSELT NUMBER FOR 100 TO 500RPM}

Figures 3 and 4 shows the difference in heat transfer coefficient and number of nuns in the nanofluid for each RPM. 5 (a) and (b), however, the heat transfer coefficient and the number of nuclei for RPM changes of the same $1 \% \mathrm{Al}_{2} \mathrm{O}_{3}$ can be confirmed. The heat transfer rate and the number of nusselts are significantly lower than those of 300 and 500 RPM . However, at 300 RPM, it can be confirmed that the heat transfer coefficient and the number are higher than 500 RPM in the early stage.

\section{CONCLUSION}

Numerical analysis of the heat transfer of the nanofluid in the unsteady state in the small tube into which the pulsating pressure is introduced showed that the effect of the content of $\mathrm{Al}_{2} \mathrm{O}_{3}$, which is a nanofluid, was further increased in the low 100 RPM. In addition, it was confirmed that the nanofluids of $0 \%$ and $1 \%$ compared to $0 \%$ and $1 \%$ of $\mathrm{Al} 2 \mathrm{O} 3$ have a data difference of more than 2 times. In 500 RPM, the difference in content is not significant compared to 100 RPM, but nanofluids with high Al 2 O 3 The heat transfer coefficient and the number of nuns were better. And the increase in the heat transfer coefficient of the nanofluid to the RPM change shows better results as the RPM increases. Therefore, nanofluid with 
high $\mathrm{Al}_{2} \mathrm{O}_{3}$ content and high $\mathrm{RPM}$ can improve the thermoelectric coefficient and increase the number of nuts. But the CFD should be progressed with constant and transient numerical investigation parallel. Basically, It would be pace with the experiment especially different model scale study. Also, uniform heat flux sample, wall shear stress, body force researches does not include this paper. This compact size model is not usual model on the nano-fluid CFD study so these factors need to be proved.

\section{ACKNOWLEDGEMENTS}

This research was supported by Basic Science Research Program through the National Research Foundation of Korea (NRF) funded by the Ministry of Science, ICT and future Planning (No. 2017R1A2B4007620).

\section{REFERENCES}

[1] J. C. Maxwell, A Treatise on Electrictiy and Magnetism, Oxford University Press, Cambridge, 1881J. Clerk Maxwell, A Treatise on Electricity and Magnetism, 3rd ed., vol. 2. Oxford: Clarendon, 1892, pp.68-73

[2] Q. Li, Y. Xuan, Heat transfer enhancement of nanofluids, International Journal 21, pp.58-64, 2000.

[3] A.A Mohamad, and R.Viskanta: Int. J. Numerical Method in Fluid, 12, 61-81(1991)

[4] Sunghoon kim,HyeMin Son,JaeCheon Lee, The effect of eccentricity between gear and housing in involute gear pump, Journal of the Korean Society of Marine Engineering 37(6) 2013.9,631-637

[5] Yangwoo Mo,YoungTae Yoo,GeeDae Na,JiHwan Kim, A Characteristics of Impedance Propagation by the Unsteady Flow in a Hydraulic Pipeline, Journal of the Korean Society of Manufacturing Technology Engineers 13(6), 2004.12, 48-55

[6] M. Nazififard, M. Nematollahi, K. Jafarpur, K. Y. Suh, Numerical Simulation of Water-Based Alumina Nanofluid in Subchannel Geometry, Science and Technology of Nuclear Installations, Vol 2012, 2012

[7] ANSYS Fluent Theroy Guide, pp. 501, November 2013

[8] V. Bianco, F. Chiacchio, O. Manca, S. Nardini, Numerical investigation of nanofluids forced convection in circular tubes, Applied Thermal Engineering 29, pp 3632-3642, 2009

[9] V. Bianco, F. Chiacchio, O. Manca, and S. Nardini, Numerical investigation on nanofluids turbulent convection heat transfer inside a circular tube, International Journal of Thermal Sciences, vol. 50, no. 3, pp 341-349, 2011

[10] Chungseub Yi ,kyujin shim,wanda ali akbar,hanshik chung,hyomin Jeong, study on the Pressure Variation in a Chamber Caused by Pulsation Pressure, Transaction of Korean Society of Automotive Engineers 15(4),2007.7, 132-138(7pages) 